\title{
Impact of HIV/AIDS Scourge on Student Athletes and Their School Environment
}

\author{
Stanley Alaubi, Deemua G.A \\ Department of Human Kinetics and Health Education, Faculty of Education, \\ University of Port Harcourt, Rivers State, Nigeria \\ Email: alaubistanley@gmail.com
}

\begin{abstract}
The presence of HIV-infected individuals in a school affects social interactions in the institution itself and in the surrounding community. The relationship of student athletes to one another or to their teacher is affected when it becomes known that a student or teacher is suffering from AIDS. In some cases there might be parental objections to the continued presence in school of an infected student athletes or teacher. Where this occurs, the school authorities need to be firm in their stance against any form of discriminatory treatment. At the same time, they have a responsibility to educate and sensitize the objections so that the opposition is withdrawn. In this they need the clear support of higher level policies and decisions that protect the rights of HIV-infected students/athletes teacher and other staff. They also need carefully worked out procedure, guidelines, information sheets and posters that clearly differentiate no-risk situations from those where there is risk of infection. Recommendation includes more purposeful use of the resources interest in persons living with HIV/AIDS, community members and students/athletes.
\end{abstract}

Keywords: HIV/AIDS Scourge, Student Athletes and School Environment.

\section{Introduction}

It is only recently that educational planner shave began to take stock of the need to address the issue of HIV/AID. This work describes how, in some countries, the epidemic is undermining the education system in the same insidious way as it undermines the human body. Schools are struggling to survive under the strain of reducing teaching capacity, reduced community support, lack of adequate planning and reduced public funding. Despair has set in and many of those affected by the crisis and its daily ordeals are questioning the relevant of education at all.

This work stresses the need for the education system to react quickly and to envisage new, creative solutions. Indeed, education has a vital role to play in combating the epidemic, both in coping with the crisis here and now, and also because the 'widow of hope', or least affected segment of the population, consists of school aged children reduced coaching capacity of an athletes, reduced community support, lack of adequate planning and reduced public funding of sports activity.

This work stresses the need for knowledge of HIV/AIDDS among athletes in the school environment to avoid feigning ignorance, thereby increasing the community spread among the school system, which will help in combating the epidemic. The knowledge on how to cope with the crisis here and now will be beneficial to the athletes, coaches' teachers and the school community at large.

There is no set formula for dealing with the situation. Each country, each community, each school will have to search for the strategies most suited to their case. However, it is necessarily to break the silence that shrouds the issue. This work will be invaluable to teachers and planners alike, as well as to all those concerned by the question of HIV/AIDS.

The purpose of the work includes monitoring the evolution and change in educational policies and their effect upon educational planning requirements; highlighting current issues of educational planning and analysing them in the context of their historical and societal setting; and disseminating methodologies of planning which can be applied in the context of both the developed and the developing countries.

HIV/AIDS affects the demand for education because there will be:

- Fewer children to educate;

- Fewer children wanting to be educated; 
- Fewer children able to complete their schooling (Kelly, 2000).

The purpose of this work is to create awareness of HIV/AIDS among athletes in the school environment, monitoring the educational policies to accommodate athletes and those living with $\mathrm{HIV} / \mathrm{AIDS}$.

HIV/AIDS will participation in sports because there will be:

- Fewer athletes in sports

- Fewer athletes desiring to participate in sports

- Fewer athletes able to reach their peak in sports

\section{Demographic Impact on the Number of School Aged Athletes}

At the macro level, AIDS will have the long term effect of population being significantly smaller than they would have been in the absence of AIDS (Table 1). in each of Botswana, Malawi, Zambia and Zimbabwe, one outcome of the AIDS pandemic is that the population in 2010 are projected to be smaller about a quarter than they would otherwise have been, while in other countries in Sub-Saharan Africa, populations will remain considerably smaller than if there had been no aids. These losses will be due to four factors:

1. Large interest in adult mortality

2. Significant increases in AIDS-related child mortality: the possibility exists that in Malawi, Zambia, and Zimbabwe infant and child mortality rates, already very high, may increase dramatically - the infant rate doubling and the child rate tripling (Hunter and Fall, 1998, pg9).

3. A lower fertility rate: it is now known that HIV impairs a woman fertility, resulting in an infected woman bearing 20 percent fewer children in births because of the premature death of women in their child-bearing years (UNESCO, 2000)

Table 1. Projected demographic impact of HIV/AIDS in selected countries 2010

\begin{tabular}{l|cc|ccc}
\hline & \multicolumn{3}{|c|}{ Population (million) } & \multicolumn{3}{c}{ Population } \\
\cline { 2 - 6 } & $\begin{array}{c}\text { Without } \\
\text { AIDS }\end{array}$ & $\begin{array}{c}\text { With } \\
\text { AIDS }\end{array}$ & $\begin{array}{c}\text { Loss to } \\
\text { AIDS }\end{array}$ & $\begin{array}{c}\text { Percentage loss } \\
\text { to AIDS }\end{array}$ & $\begin{array}{c}\text { Life expectancy } \\
\text { (year) }\end{array}$ \\
\hline Botswana & 21 & 1.6 & 0.5 & 23.8 & 33.4 \\
Dem.Rep. Congo & 74.6 & 69.3 & 5.3 & 7.1 & 51.3 \\
Cote d'Ivoire & 23.5 & 20.3 & 3.2 & 13.6 & 44.8 \\
Ethiopia & 87.0 & 81.2 & 5.8 & 6.7 & 51.3 \\
Kenya & 39.1 & 33.9 & 5.2 & 13.3 & 43.2 \\
Malawi & 14.1 & 10.7 & 3.4 & 24.1 & 29.5 \\
South Africa & 53.6 & 49.2 & 4.4 & 8.2 & 47.8 \\
Tanzania & 43.9 & 36.1 & 7.8 & 17.8 & 36.5 \\
Uganda & 32.7 & 26.4 & 6.3 & 19.3 & 35.2 \\
Zambia & 15.7 & 11.5 & 4.2 & 26.8 & 30.3 \\
Zimbabwe & 16.4 & 11.9 & 4.5 & 27.4 & 33.3 \\
\hline
\end{tabular}

Source: Hunter and Williamson, 1997: Fig. A - 1

The demographic development will result in the number of athletes of school going age being smaller than it would otherwise have been. An AIDS assessment and planning study for Tanzania projected that in the worst case scenario, at the primary level there would be 22 percent fewer children to be educated, and at the secondary level, the relevant age-groups would be reduced by about 14 percent (World Bank 1993, p.68). More so recent estimates for other countries point in the same direction: in a matter of decade, the number of children of primary school age will be lower than if there had been no AIDS.

\section{Economic Impact on Participation in Sports Programme}

Regardless of how free an education system or activity purports to be, the recipient must always bear some direct cash costs, indirect costs, opportunity costs, or all of them. Apart from the direct cash cost 
of tuition fees, athletes in the majority of countries are faced with indirect cost. There refer to cash payments for such items as educational materials (textbooks, exercise books, ball-pens, pencil etc); school related activities (clubs, sports, other recreational activities; school or parent teacher association levies for school developments, supplies or maintenance; additional tuition; and uniforms. Where HIV/AIDS is prevalent, cash may not be available for these purposes. There are many reasons for this: according to UNESCO (2000), the family wage-earner may have had to reduce its agricultural production because of sickness or deaths or because the only ones who can engage in agricultural work are the surviving old people or those who are very young; limited family cash resources may be consumed in care for the sick, traveling to clinics grasping at what are claimed to be remedies, because of the deaths of other family members.

All of these circumstances currently affect millions of athletes. The AIDS generated pressure on the limited cash resources available to their families means that less is available for education. Because of HIV/AIDS, their families cannot afford to send them to school. This is confirmed by interviews with Lusaka teachers whose classes included pupils whose parents had died of AIDS. All reported that, following the death of the parent, the athletes stopped attending because of school fees and the costs of school requisites (UNICEF, 2002).

Opportunity costs also creates a substantial barrier to participation in school sports and other educational programmes children or young people may be needed in the AIDS stricken home to care for or stay with the sick; to free up an adult from domestic or economic activities so that the adult can care for the sick; to care for younger siblings; to take over an adults income-generating activities; to accompany sick persons to health-care centers; to head household because of the death or terminal sickness of parents. Where these demands for the Childs labour are intermittent, they lead to considerable late-coming to training of repeated absence from school, factors which adversely affect the learning achievement of the athlete which may ultimately lead to termination of school sports participation.

\section{Attitudinal Impacts of HIV/AIDS on School Participation}

Because of HIV/AIDS in their families, many athletes do not want to attend school. For some, the deterrent is fear of the stigma and scorn that they may encounter in school - the mockery of their school mates, the pointed remark. The sudden silence, the fears of other parents, the exclusion and ostracism, the reduced availability of ready money, the external signs of increasing poverty. Teachers in many countries acknowledge the difficulties these heavily traumatized athletes experience in learning. They are aware that the minds of these athletes are locked in a state of prolonged shock and that they are in dire need of counseling and support. They know also that there are many other athletes in the community who do everything possible to avoid attending school once AIDS has struck in their families.

\section{Parental Disillusion}

An emerging psychological factor is a sense of fatalism in parents. In some heavily infected countries, these are beginning to question the value of sending children to school when it seems likely that even these athletes will die young before they have been able to garner any economic returns for what was spent on their education. This hopelessness broods heavily with them and communicates itself to them, who likewise question whether a substantial part of the few years they will have of life should be spent in school. Because AIDS is so rampant in their communities and possibly in their families, they do not want to be educated UNICEF (2002).

The AIDS-driven fatalism to school participation works in synergy with negative attitudes arising from parental disillusion with the quality of educational provision, a disillusion which itself is AIDS related. Parents show disinclination to send children to school because little learning is occurring, teachers are frequently absent. All of these are factors in which AIDS can play a role. Although no rigorous studies have been conducted, it seems likely that some of the parental disillusion which is already leading in some countries to a decline in school sports participation rooted in the way AIDS is impacting on the quality and relevance of educational provision. 
Bank, A.A. (2002) emphasized that some parents are also put off by the apparent correlation that existed in the past between educational status and HIV risk. They further emphasized that parents are frightened by what they see, that HIV appears to occur more commonly among the educated. They may value education as opening the door to greater prosperity, but they do not want to expose their children to risk of HIV infection.

\section{Gender Implication}

Hepburn (2001) explained that almost invariably, when demand for education falters, the first one to be negatively affected is the girl, above all the girls in a rural setting. This is the case in virtually all the situations considered above. If there are problems in meeting the cash costs of education, a boy will be favored in preference to a girl. Because many societies considered that a girl's place is in the home, it is the girl rather than the boy who is likely to be deprived of educational opportunities through the need to provide domestic care and services in an AID-stricken household. Parents who fear that their children will know a short life want to see their daughters married at an early age so that they can bear as many children as possible in the short time available to them, and thereby ensure the continuity of the family.

Because the cultures of almost every society socialize boys to be strongly masculine, dominant and emotionally self-possessed, boys who have been traumatized by the experience of AIDS may seek to repress their emotional disturbance (very likely to their eventual damage) and continue to attend school. Girls on the other hand, are frequently socialized to be submissive, yielding, dependent, and emotionally more demonstrative, and hence are more likely to remain or be kept away from school because of AIDS trauma. Wijingaarden and Shaeffer (2003) also asserted that it seems certain that HIV/AIDS has motivated older men, especially 'sugar daddy' type to turn to young girls for sex, in the belief they are HIV-free.

There is also some turning for sex to young uninfected girls in the false belief that such an encounter would provide a cure for HIV infection. Both practices place girls at enormous risk. Aware of these practices, and to some extent of the associated risks, some parents do not allow their daughters to attend or other educational programmes, especially if there is some distance between girls' home and the school.

\section{Impact of HIV/AIDS on the Content of Education}

UNAIDS (2002) emphasized that HIV/AIDS affect the content of education because:

1. The need to incorporate HIV/AIDS education into the curriculum, with a view to imparting the knowledge, attitudes and skills that may help to promote safer sexual behavior;

2. The need to develop life-skill which equip pupils for positive social behavior and for coping with negative social pressures;

3. The need to establish a vigorous human rights approach;

4. The need to bring HIV and AIDS issues out into the open;

5. The need for inclusion in the curriculum of work-related training and skills, so as to prepare those compelled to leave school early (because of orphanisd or other reasons) to care for themselves, their siblings, their families.

6. The need to adjust educational content to carter for the skills society is losing through HIV/AIDS

\section{The Inclusion of HIV/AIDS in the Curriculum}

The most obvious impact of AIDS on the content of education is the incorporation of HIV/AIDS, reproductive health and life-skills education in the curriculum with a view to bringing about behavior change. The first is to determine the most appropriate and effective way of placing this subject area within the curriculum. There are three options according to UNICEF and World Bank (2002).

1. The separate subject approach, where HIV/AIDS and reproductive health are designed as a freestanding separate subject. This mode ensures that the subject is clearly identifiable and manageable. There is the further advantage that this allows HIV/AIDS and sexual health to be given a high profile as examinations to drive the desired learning. 
2. The carrier subject approach where HIV/AIDS and reproductive health become an integral part of an existing carrier subject (such as Health Education). The difficulty with this approach is that the new areas will receive only as much emphasis, from learners and teachers, as attaches to the carrier subject. There is also some possibilities that the new areas might lose their identity within the carrier subject.

3. The integration approach where HIV/AIDS and reproductive health care taken to be crosscutting issues to be addressed in all subject areas and become examinable as part of those subjects. In this approach also there is some risk that the new areas would receive adequate treatment from more and would not go beyond knowledge aspects.

The second management and planning issue in this field concerns the central role teachers must play if effective life-skills and reproductive health programmes are to be established within school. These includes:

- The inadequacy of teacher knowledge and confidence

- Teacher embarrassment in treating of sexuality issues with the young and with those of opposite sex;

- Teacher concern about lack of preparation to teach in the areas of HIV/AIDS, reproductive health and psycho-social life skill;

- The reluctance of teachers who aware that they or members of their families are HIV-infected to teach something which is so painfully close home;

- Teachers feelings that this is not what education is about;

- Teachers anxiety that in dealing with sexuality and sexual behavior they would break traditional taboos and offend parents; and

- The low credibility teachers may have because of their own high level of infection.

\section{Human Rights Approach}

Human Rights and HIV/AIDS issues are intimately connected. An environment in which human rights are respected ensures that vulnerability to HIV/AIDS is reduced, those infected with and affected by HIV/AIDS live a life of dignity without discrimination, and the personal and societal impact of HIV infection is alleviated (UNAIDS, 1999). The education system has a responsibility to protect the human rights of each one of its members, from the high-placed official down to the lowliest employee or the youngest school child. Educational institutions likewise have a responsibility to ensure that the human rights area maintains a high profile in the full range of their curricular and co-curricular activities.

Educational managers and school officials need to ensure that they do not fall into the trap of denying access to HIV-infected students, because of their HIV status, makes it difficult for the students in question to meet attendance requirements or pay educational cost. They must also ensure that they do not unreasonably restrict the participation of infected students in certain curricular and co-curricular activities.

Education officials at all levels must also ensure that they protect the rights of HIV-infected teachers and other employees, while school authorities should strive to protect student athletes from witnessing some of the more humiliating effects of HIV/AIDS in teachers and other employees. But this must always be done in a way that increases and does not demean the dignity of the affected individual. No matter how troublesome their illness, teachers and other education employees maintain their rights as human beings.

Education ministries and teaching research institutions need to develop and implement provisions for dealing with these and other aspects of human rights and education. They should also develop guidelines for us by schools and colleges.

\section{Peer Group Influence}

When a member of the school community begins to show the signs of AIDS, others in the group can be motivated by a mixture of fear, bewilderment and dismay. They fear infection, they are distraught at the rapid changes they see occurring. Conflicting emotions may lead to the affected individual being isolated and possibly excluded from peer groups. Kelly (2000) emphasized that this can also lead to 
patronizing and condescending attitudes which leave a further scar on the infected person. In addition to the social encounters, the entire teaching and learning process may be affected when students witness the rapid physical deterioration of a classmate or teacher with full-blown AIDS. Trauma arising from the experience of the way AIDS can incapacitated and humiliate a fellow human being, especially when this occurs in school surroundings, can have a shattering impact on a young person's psychological stability and learning capacity.

\section{Conclusion}

There can be few rules or regulations appropriate to AIDS situations. Nevertheless, the entire education system should ensure that it never defaults in its responsibilities to persons living with HIV/AIDS. It should alert every responsible officer every teacher, every students/athletes to the need for sensitivity, understanding and delicate thoughtfulness. It should take whatever actions are needed to ensure that members of a school community who live with the disease can live full, productive and happy lives.

\section{Recommendation}

Responding to the challenge of designing sports education in a world with AIDS requires that educational policy-makers and planners manifest certain qualities and adopt certain approaches. These would include:

1. great flexibility;

2. tolerance for a diversity of solution and models;

3. willingness to loosen up bureaucratic constraints and procedures;

4. much resourcefulness and openness to change;

5. co-operation and collaboration with several partners from other government sectors, civil society, communities, the churches;

6. more purposeful use of the resources inherent in persons living with HIV/AIDS, community members and student athletes;

7. enhance understanding of what sports education is all about; and

8. sensitivity to the needs of those infected or affected by HIV, the poor and those in difficult circumstances.

\section{References}

1. Brink, A.A. (2002). Vulnerable children with HIV/AIDS. HIV and developing programmes, Issues paper No. 32, New York: $1117-8$

2. Hepburn, A. (2001). Primary education in eastern and southern Africa: Increasing access for orphans and vulnerable children in AIDS-infected areas. At http://www.ussaidgov/pophealth/cofwu.Hepburn.html.

3. Hyath, R.W. (1977). Intra-mural Sports Organization and Administration, London, the C.V Mosby Co.

4. Irwin, R.L, Sutton W. A., \& McCarthy, L. M. (2002). Sport Promotion and Sale Management, U.S.A. Human Kinetics.

5. James, M. (2006). Liability for Professional Athletes' Injuries: A comprehensive Analysis of Where the Risk lies. Web Journal of Current Legal Issues. [Online] Available: Webjcli.ncl.uk/2006/issue1/james/.htm/

6. Kelly, M.J. (2000). Planning for education in the centered HIV/AIDS. Paris United nations Educational, Scientific Organization Publishers.

7. Kenneth D. Moore. (1989). Classroom Teaching Skills. Cameron University Random House New York.

8. Ojeme E, O. (1983) physical Education Curriculum in Nigeria Universities. An Appraisal of Undergraduate Programme. Amen Journal Vol. 3, No. 1.

9. Okundare, A. A. (2014) Sports Development, Problems and Prospects in Nigeria. JONAPHER-SD Journal of University of Port Harcourt.

10. UNAIDS (1999). Reducing Girls vulnerability to HIV/AIDS: The Thus approach. Geneva, Switzerland.

11. UNAIDS (2002). Implementation of the UNGASS declaration of commitment on HIV/AIDS: Care indicators. Geneva. Switzerland. 
12. UNESCO (2000). Implementation for all. Dakar framework for action. http://www.unescoforall/ framework.shtml.

13. UNICEF, Eastern and South Africa Region (2002). Eastern and Southern Africa regional workshop on children affected by HIV/AIDS, Kenya.

14. UNICEF and World Bank (2002). Ensuring educational access for orphans and vulnerable children: A training module, New York.

15. Wijingaarden, J. \& Shaeffer, S. (2003). The impact of HIV/AIDS on children and young people: Reviewing research conducted and distilling implications for the education sector in Asia UNESCO, Bangkok.

16. World Bank, The Partnership for Child Development, UNICEF, UNAIDS (2002). Ensuring education access for orphans and vulnerable children. Washington D.C. 